\title{
Design of PI Controller for Voltage Controller of Four-Phase Interleaved Boost Converter Using Particle Swarm Optimization
}

\author{
Ittipon Laoprom (iD) and Satean Tunyasrirut $(\mathbb{D}$ \\ Department of Electrical Engineering, Faculty of Engineering, Pathumwan Institute of Technology, Bangkok 10330, Thailand \\ Correspondence should be addressed to Ittipon Laoprom; oodood.kp@gmail.com
}

Received 26 October 2019; Accepted 18 January 2020; Published 16 March 2020

Academic Editor: Michela Robba

Copyright (C) 2020 Ittipon Laoprom and Satean Tunyasrirut. This is an open access article distributed under the Creative Commons Attribution License, which permits unrestricted use, distribution, and reproduction in any medium, provided the original work is properly cited.

\begin{abstract}
This article introduces voltage feedback controlling using the PI controller tuned gains by metaheuristic optimizations for a fourphase interleaved boost converter. The metaheuristic optimizations, particle swarm optimization (PSO), genetic algorithm (GA), and Tabu search (TS) are applied to find the optimal gains for the proposed control system. In experiment, the designed control system is implemented on the DSP board TMS320F28335 with MATLAB/Simulink. In this paper, there are two conditions of the control system in the test, without load and with load. The response result of the proposed control system tuned gains by PSO is no overshoot and approaches to the steady state better than GA and TS methods. Moreover, it is able to maintain the output voltage feedback at a constant level according to the control signal both without load and with load conditions. As a result, the four-phase interleaved boost converter is regulated by the PI controller tuned gains with PSO which could efficiently maintain the voltage of both levels.
\end{abstract}

\section{Introduction}

Currently, the need for energy is increasing. It is necessary to find energy from other possible resources, for example, solar energy, wind energy, and fuel energy. In general, to bring alternative energies to use, it is necessary to increase or reduce the voltage level before the actual use. This is to make it conform with certain equipment. For increasing the voltage, a power electronic circuit is required. The boost converter is one of the circuits used for increasing voltage. The boost converter circuit is a circuit that uses less equipment and can raise the voltage. For this reason, it is one of the popular circuits used to increase the voltage for further applications $[1,2]$.

Due to the increasing need for energies, at present the use of a single energy transforming set is not enough for serving the purpose. Thus, devices that work together in parallel are used to serve an increasing need for energies, and using only one boost converter which requires high energy might not be possible. So, it is necessary to have devices that work together in parallel in order to share the burden of increasing need for energies.
However, when the boost converter works in parallel, it will create a high ripple of input and output voltage. For this reason, the operation of each set of the boost converter connected in parallel is set for working at appropriate degrees. This is to reduce the ripple of input and output current, and as a consequence, the output voltage has less ripple. The boost converter in parallel has been applied to various works like the use of power factor correction (PFC) in experiment rooms, the application for solar energy, fuel cell, and DC-DC switched-mode power converters (SMPC) [3-8].

However, though the voltage has less ripple, with no system to control the voltage output size to be constant when brought into actual use could possibly affect the stability of the system, for example, change from lower load to higher load. This will cause the reduction of output voltage to become smaller than the required size. The same applies to changing from higher to lower load, and this will cause output voltage higher than that required. Because of this, it is very important to have a system to control output voltage in order to keep the output voltage constant, though there is a 
change in output or input load. For certain types of work, having only one PI controller is sufficient for controlling the process to be stable, and its result of controlling using the PI controller is acceptable.

There are various ways to adjust the value of the Proportional-Integral (PI) controller, and currently, artificial intelligence plays an important role in searching suitable values. Examples are Tabu search (TS), genetic search (GS), and particle swarm optimization (PSO). The PSO, in particular, is a method to give a suitable value and has been used with many systems of PSO such as the DC motor control system, the one without carbon brush, the DC-to-DC converter circuit system, the test on the electric motor drive, and the multilevel inverter. The applications on the abovementioned systems gave a very satisfactory result, and using the search values with the test system also provided a satisfactory response [9-14].

As mentioned previously, the PSO is widely applied to the PI controller for simulation system and real-world system. However, it is usually employed in one-phase and two-phase interleaved boost converter circuits. There are a few studies considering the gained value PI controller for real system of the four-phase interleaved boost converter circuit. This research introduces a design of the PI controller using PSO search for controlling the voltage of the four-phase interleaved boost converter in order to control output voltage at constant size throughout the use. The technique used was by PSO to control output voltage to have constant size according to the set voltage both when the load is constant and while the load is changed. The circuit keeps reducing the input and output voltage ripple as usual, so that it is possible to be used for further work related to increasing voltage level.

\section{Theory of Boost Converter}

The boost converter circuit is a power converter circuit that works to increase output voltage to be higher than that of the input. The structure of the circuit is shown in Figure 1.

\subsection{Theory of Four-Phase Interleaved Boost Converter Circuit.} The four-phase interleaved boost converter is a circuit designed based on the original boost converter. The original boost converter is designed to work in parallel while the circuit operation is interleaved. The interleave depends on the number of the parallel boost converters while the fourphase interleaved boost converter helps to solve the problem of overload burden the original boost converter has. As the circuit load increases, it is necessary to design larger equipment as a result. Also, switch operation will get a higher load as a result. Four-phase interleaved boost converter can solve this problem. This also helped in reducing the ripple of input and output. The four-phase interleaved boost converter circuit [15-18] is shown in Figure 2.

Operation of the four-phase interleaved boost converter circuit is shown in Figures 3-6 [16-18].

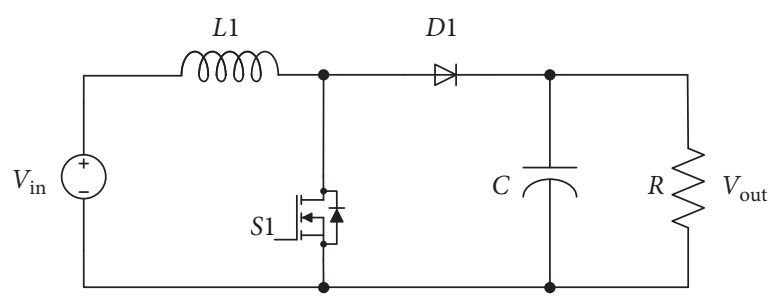

FIgURE 1: Original boost converter.

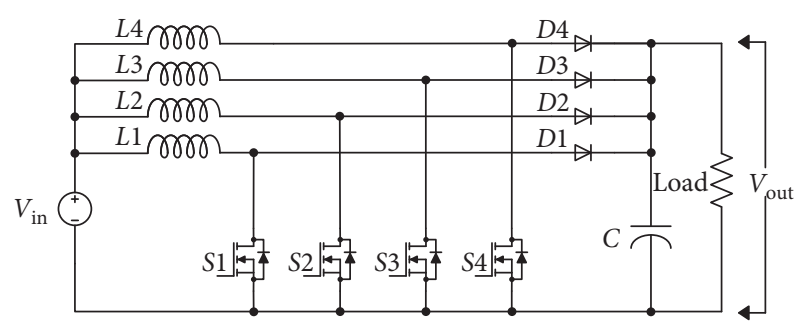

FIgURE 2: Four-phase interleaved boost converter circuit.

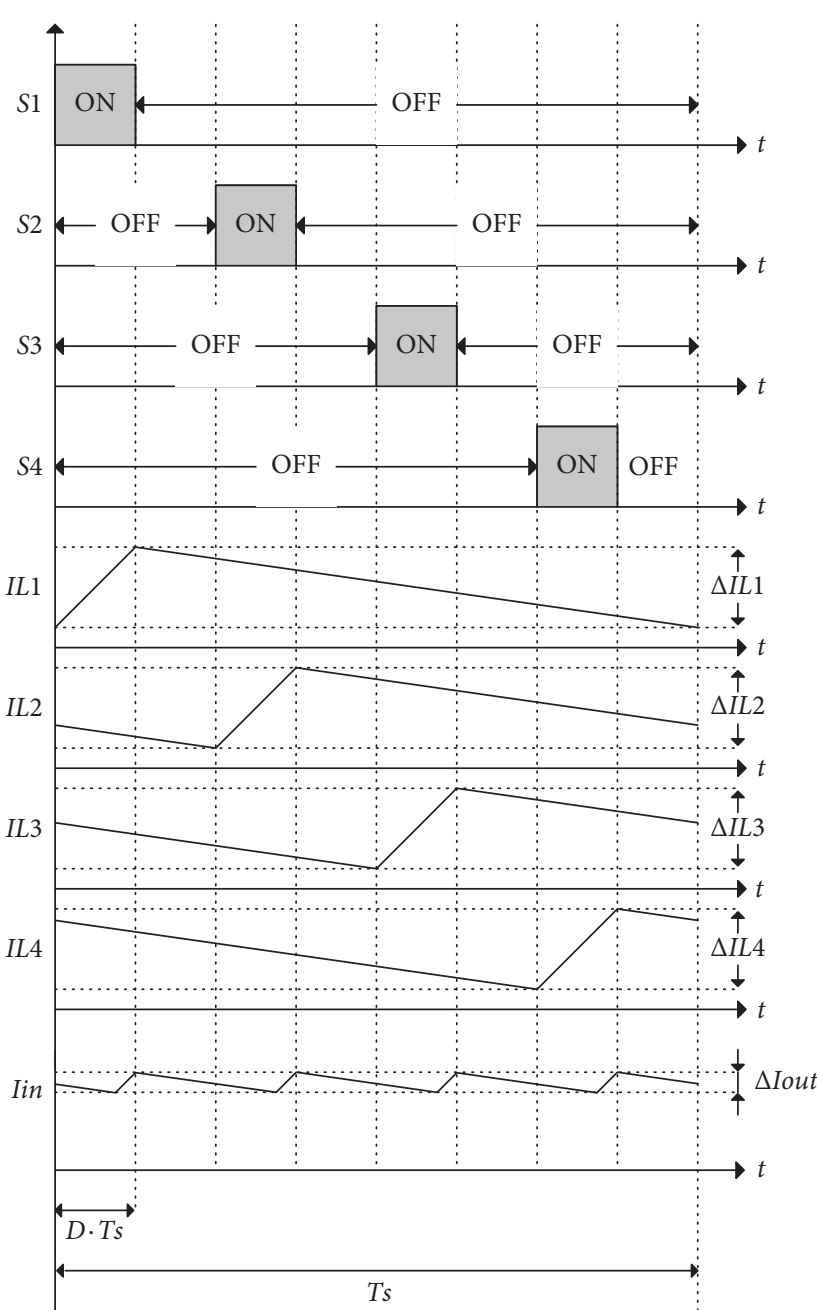

FIGURE 3: Switching pattern and inductor current waveform in range of the duty ratio less than $1 / 4$. 


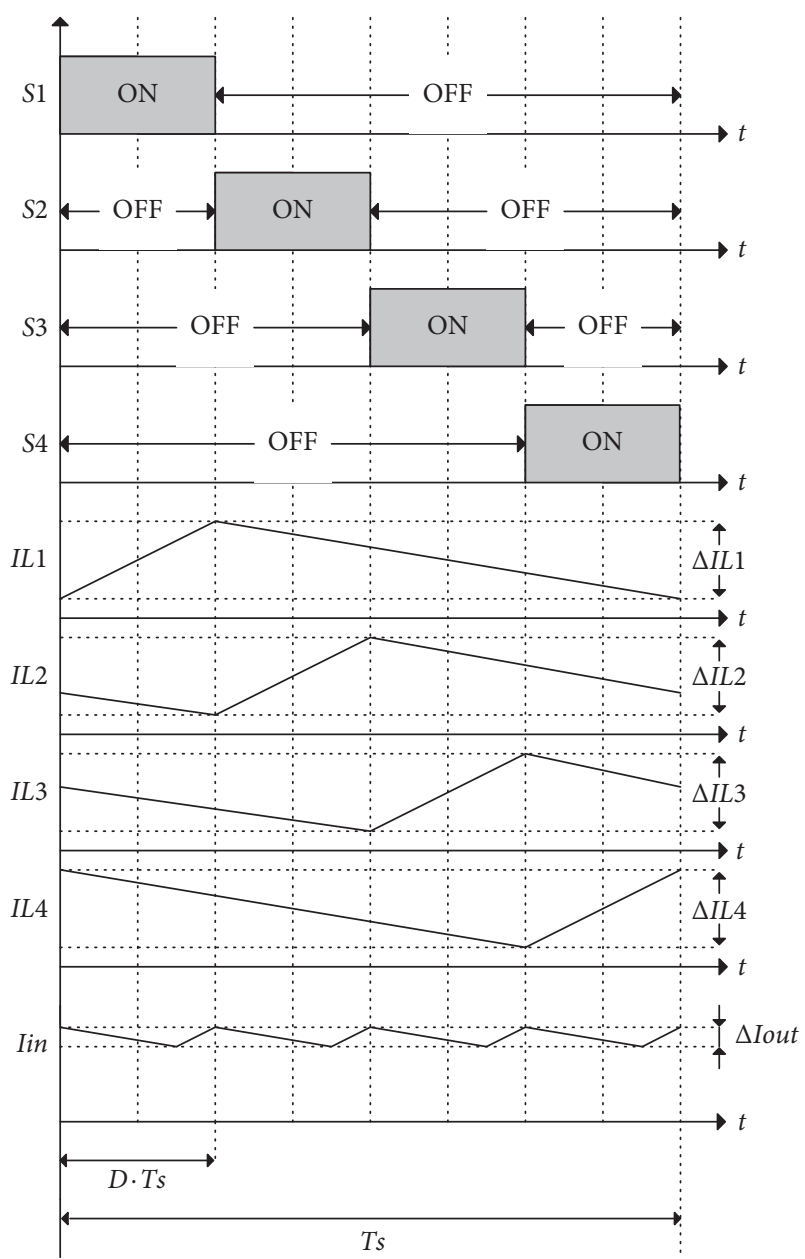

FIGURE 4: Switching pattern and inductor current waveform in range of duty ratio as $1 / 4$.

2.2. Design of Different Parameter Values. Design of different parameter values can be performed as follows.

The equation for designing duty cycle for switching can be designed using the following equations:

$$
\begin{aligned}
V_{\text {output }} & =\frac{V_{\text {input }}}{1-D}, \\
D & =1-\left[\frac{V_{\text {input }}}{V_{\text {output }}}\right],
\end{aligned}
$$

where $D$ is duty cycle, $V_{\text {input }}$ is voltage input, and $V_{\text {output }}$ is voltage output.

The equation for designing inductance value can be derived using the following equation:

$$
L 1=L 2=L 3=L 4=\frac{V_{\text {input }} D}{\Delta I_{L} f_{s}},
$$

where $L$ is inductor, $\Delta I_{L}$ is induction ripple current, and $f_{S}$ is switching frequency.

The equation for designing capacitor value can be derived form the following equation:

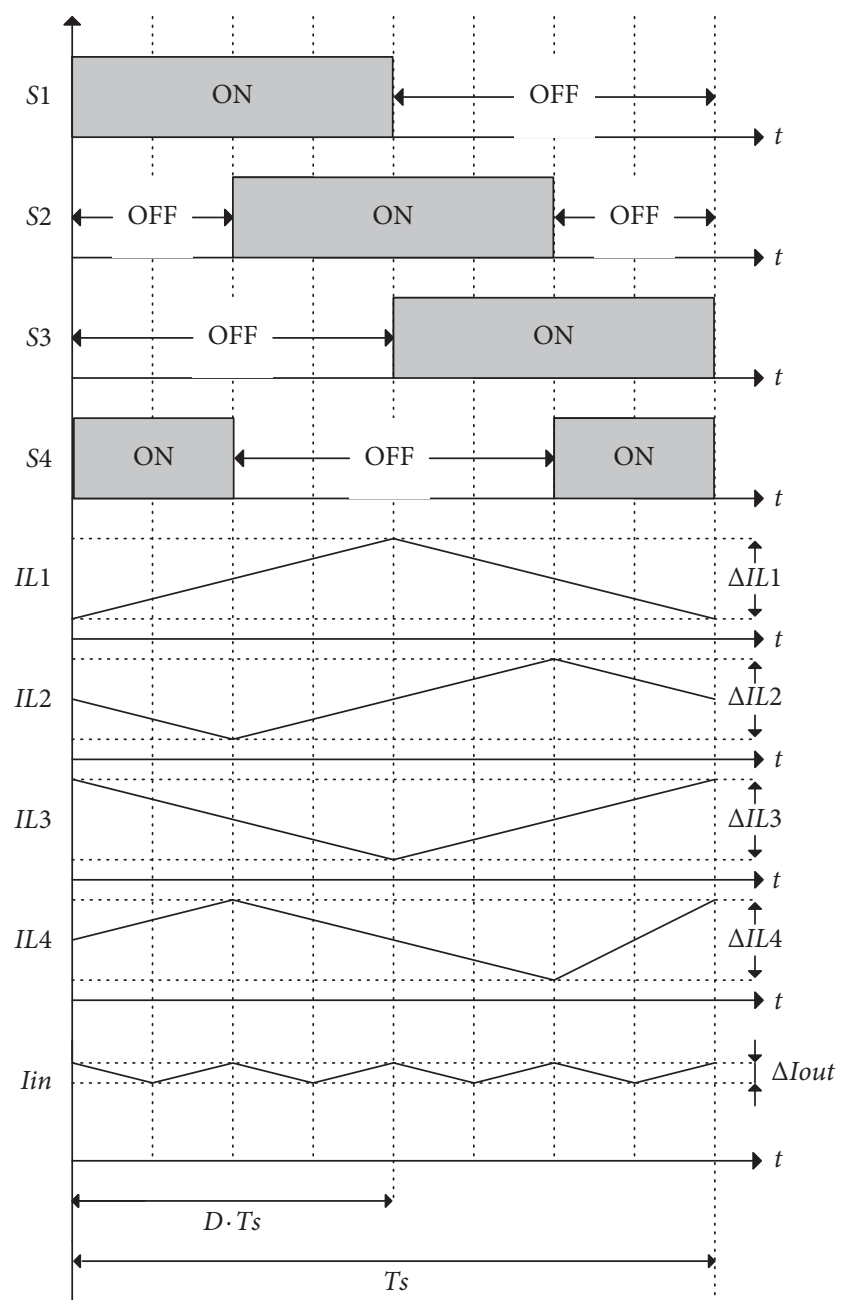

FIGURE 5: Switching pattern and inductor current waveform in range of duty ratio as $1 / 2$.

$$
C=\frac{V_{\text {output }} D}{R f_{s} \Delta V_{\text {output }}},
$$

where $C$ is capacitor, $R$ is resistor load, and $\Delta V_{\text {output }}$ is a ripple factor of the output voltage.

For designing the angle of the boost converter in each phase, the switching angle of the boost converter in each phase can be designed to form the following equation:

$$
\theta=\frac{360}{N}
$$

where $\theta$ is angle of switching and $N$ is number of phases of the boost converter circuit.

\section{Algorithm of PSO}

The origin of searching the most suitable value of PSO was developed by Reynolds in 1987 [19, 20]. He got inspiration from the patterns of herd movement such as flock of birds, school of fish, and insect swarm as shown in Figure 7. The movement is based on three main principles: confrontation avoidance of swarm, same speed control within the swarm, 


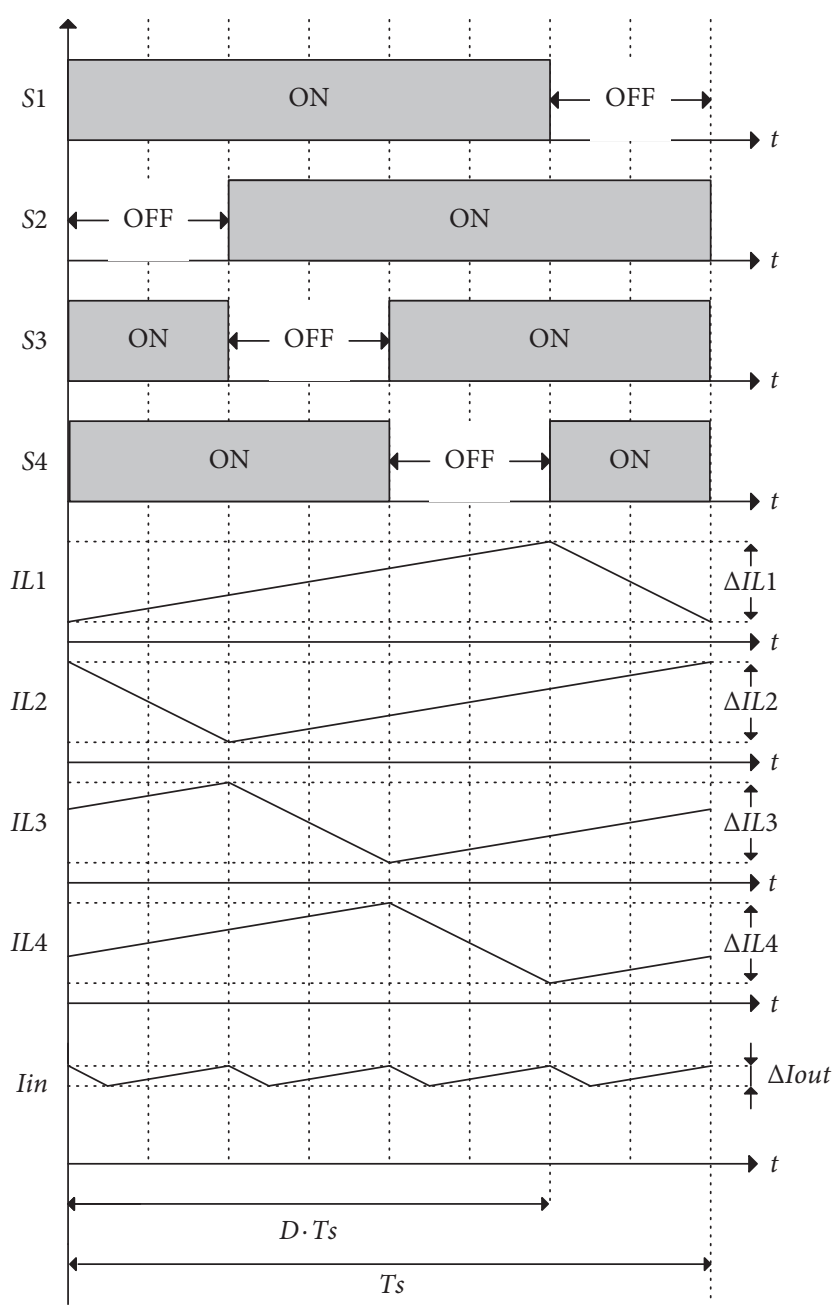

FIGURE 6: Switching pattern and inductor current waveform in range of duty ratio as 3/4.

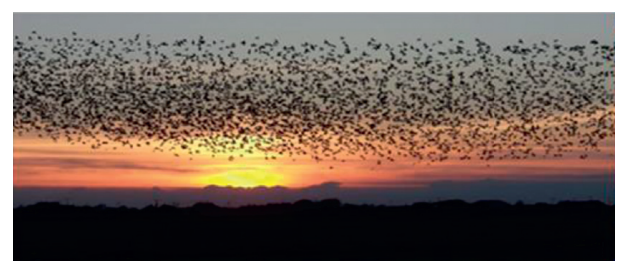

(a)

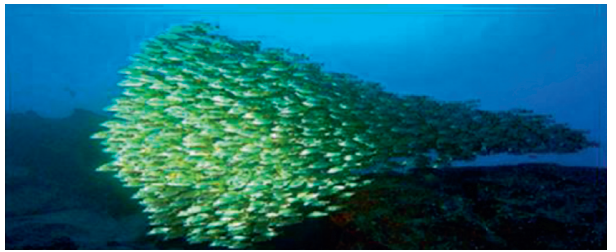

(c)

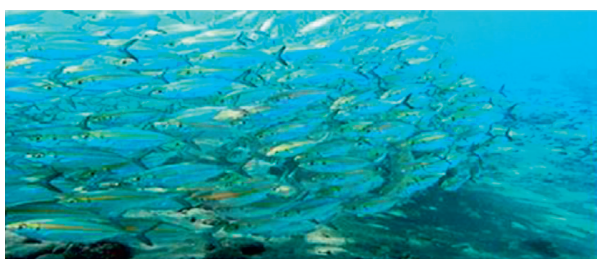

(b)

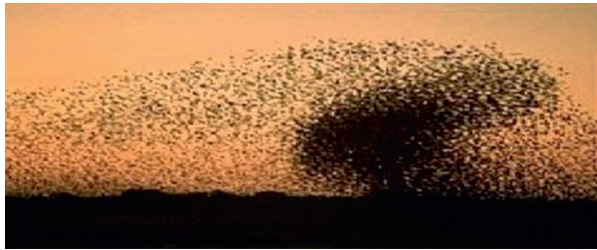

(d)

Figure 7: The movement of flock of birds, school of fish, and insect swarm used as a guideline for particle swarm search.

and moving to the center of the swarm. These principles lead to the swarm behavior in nature, i.e., self-defense from being hunted and searching for food resources effectively. Later, in
1995, Kennedy and Eberhart developed PSO as an effective tool for solving the problem of obtaining the most suitable value [21]. 
Algorithm of PSO has the same feature of evolutionary calculation, i.e., there will be a creation of population called particle which will move around the search space. Each particle has a speed vector and a memory unit to be used for storing previous good answers. $p_{\text {best }}$ is set as good answer in the current search while $g_{\text {best }}$ is set as global solution. All particles will move in a similar manner, and the ones closest to the target are the strongest. With the particle swarm movement principle, the rest of the particles will be adjusted to have a similar movement direction as that of those strongest ones. This makes it possible for the whole particle swarm to move to the target effectively.

Consider that the search-space is d-dimensional and at particle $i$-th in the swarm. It can be defined as $X_{i}=\left(x_{i 1}, x_{i 2}, \ldots, x_{i d}\right)$ and the velocity can be represented by another d-dimensional vector as $V_{i}=\left(v_{i 1}, v_{i 2}, \ldots, v_{i d}\right)$ and the best previously visited position of this particle be denoted by $P_{i}=\left(p_{i 1}, p_{i 2}, \ldots, p_{i d}\right)$. The adjustment of particle movement direction and the answers found are shown in equations (6) and (7) accordingly [22]. Where $x$ is a particle or answer, $v$ is speed vector showing adjusted direction, $w$ is inertia weight, $c_{1}$ is cognitive acceleration, $c_{2}$ is social acceleration, and $r_{1}$ and $r_{2}$ are random numbers uniformly distributed in the range $[0,1]$.

In case of $2 \mathrm{D}$ space, the movement of particles should be adjusted as shown in Figure 8.

$$
\begin{aligned}
& v_{i d}^{n+1}=w v_{i d}^{n}+c_{1} r_{1}^{n}\left(x_{i d}^{p_{\text {best }}}-x_{i d}^{n}\right)+c_{2} r_{2}\left(x_{i d}^{g_{\text {best }}}-x_{i d}^{n}\right), \\
& x_{i d}^{n+1}=x_{i d}^{n}+v_{i d}^{n+1} .
\end{aligned}
$$

The inertial weight $w$ can be calculated from the relation as in equation (8), where $w_{\max }$ is the maximum weight, $w_{\min }$ is the minimum weight, $k_{\max }$ is the number of the highest search round set, and $k$ is the current search round. The best value suitable for use is the number of current search round, and the most suitable value of work application is $c_{1}$ and $c_{2}$ which should be in-between 1 and 2 while $w_{\min }$ and $w_{\max }$ should be equal to 0.4 and 0.9 accordingly [23]. Algorithm of PSO has the following details:

$$
w_{i}=w_{\max }-k\left(\frac{w_{\max }-w_{\min }}{k_{\max }}\right) .
$$

The steps of designing PSO are as follows:

Step 1: setting initial values which are search space, number of particles, and maximum number of search rounds.

Step 2: creating particles with normal sampling distribution according to the number set.

Step 3: evaluating the strength of each particle using objective function.

Step 4: adjusting the movement direction in accordance with the strongest particle using equations (6) and (8).

Step 5: calculating the particle of the current search round using equation (7).

Step 6: checking the ending condition. If it is correlated, this means that the best search is obtained.
Then, stop the search or perform step 3 to further the next search.

\section{Theory PI}

The PI controller is a combination between the proportional controller, P, and integral controller, I. The system for controlling PI is shown as a block diagram in Figure 9. PI controlling system is composed of error signal, $E(s)$, control signal, $U(s)$, output response signal, $C(s)$, reference signal, $R(s)$, disturbing signal, $D(s)$, and transferring signal of the system $G_{p}(s)$ and $G_{c}(s)$. The theoretical function of the PI controller is stated in the following equation:

$$
\left.G_{c}(s)\right|_{\mathrm{PI}}=K_{p}+\frac{K_{i}}{s}=\frac{K_{p} s+K_{i}}{s} .
$$

The PI controlling system is shown in Figure 9.

The four-phase interleaved boost converter system has a fast output response but lacks stability. The PI controller has the advantage of faster response times and less stable errors. Therefore, it is very appropriate to choose a PI controller for this system.

To obtain the value of the PI controller for the four-phase interleaved boost converter circuit, the design of the PI controller uses PSO search to control four-phase interleaved boost converter voltage as shown in Figure 10.

\section{Digital Signal Processor Set}

This part will focus on the digital signal processor or Digital Signal Processor (DSP) board TMS320F28335 of Texas Instruments company [24] as shown in Figure 11 for analyzing real-time controlling. The Texas Instrument TMS320F28335 consisting of a 32-bit CPU and a single-precision 32-bit floating-point. The CPU speed is controlled by a clock signal with the frequency of $150 \mathrm{MHz}$ working with MATLAB/ Simulink [25]. It produces pulse width modulation (PWM) signal for driving the four-phase interleaved boost converter circuit switch of $25 \mathrm{kHz}$ frequency as shown in Figure 12.

\section{Design of Four-Phase Interleaved Boost Converter Circuit}

The parameter value of the four-phase interleaved boost converter obtained from equations (1)-(5) is shown in Table 1.

For the design of a four-phase interleaved boost converter circuit to simplify circuit design, the four-phase interleaved boost converter has parallel circuits. Therefore, considering only one model of the circuit to make it easier to design. The transferring function of the boost converter circuit uses the impedance method where the analysis makes use of switching operation while the switch is off. This can be shown as follows [26]. All of the impedance value $\left(Z_{\text {total }}\right)$ is shown in the following equation:

$$
Z_{\text {total }}=Z_{1}(s)+Z_{2}(s)
$$

$Z_{1}(s)$ is the condition of the switch when the circuit is open, and $Z_{2}(s)$ is the condition of the switch when the 


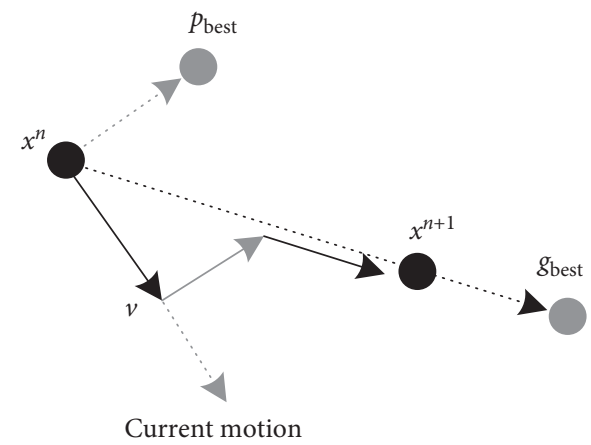

Figure 8: Movement of particles in 2D space.

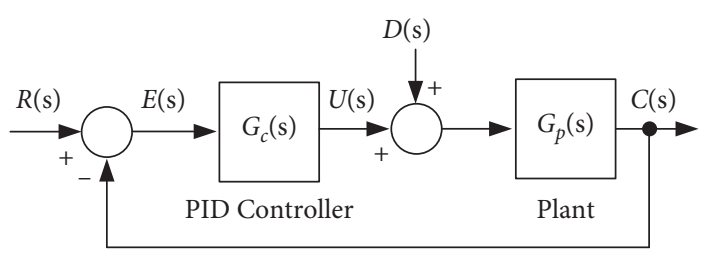

Figure 9: Operation diagram of the PI controller.

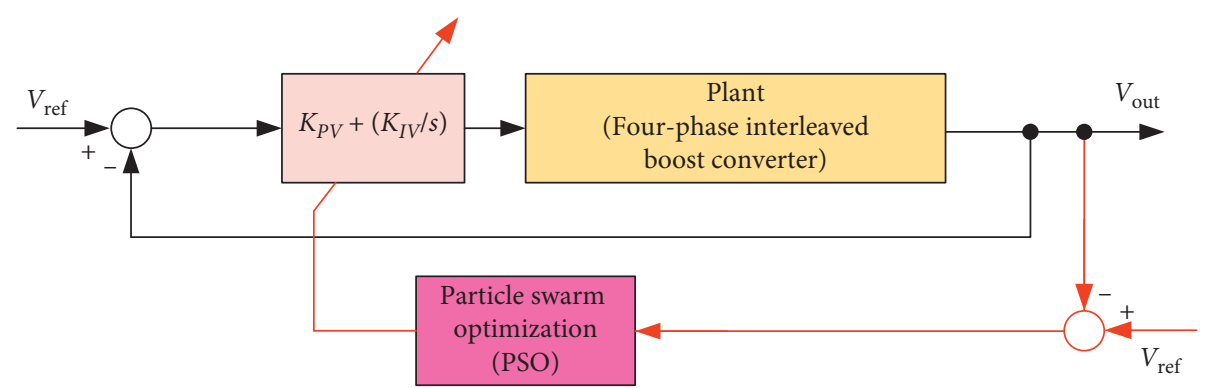

FIGURE 10: Operation diagram of the PI controller design using PSO search to control four-phase interleaved boost converter circuit voltage.

circuit is closed. The value of $Z_{1}(s)$ is shown in the following equation and the value of $Z_{2}(s)$ is shown in equation (12).

$$
\begin{aligned}
\frac{V_{\text {in }}(s)}{I(s)} & =\frac{R L C s^{2}+L s+R}{R C s+1}, \\
\frac{V_{\text {out }}(s)}{I(s)} & =\frac{R}{R C s+1},
\end{aligned}
$$

and the transferring function of the system is shown in the following equation:

$$
\frac{V_{\text {out }}(s)}{V_{\text {in }}}=\frac{R}{R L C s^{2}+L s+R},
$$

Where the value with parameter from Table 1 is replaced and the transfer function of the system is obtained, and it is shown in the following equation:

$$
G_{p}(s)=\frac{2}{117.3 \times 10^{-9} s^{2}+586.5 \times 10^{-6} s+2} .
$$

As mentioned in equation(14), the term $117.3 \times 10^{-9} \mathrm{~s}^{2}$ is a very small value considered close to zero. This system, therefore, became first order, called Type 0 system. Thus, it is suitable for the PI controller.
In designing the value of PI for the four-phase interleaved boost converter circuit using particle swarm search based on Figure 8, PSO search was used for designing a PI controller for the four-phase interleaved boost converter circuit system where PSO algorithm was made by MATLAB, working with Intel(R) Core (TM) i5-3210M @2.5 GHz. The number of particle sets is 100 where $c_{1}=c_{2}$ is $2.0, r_{1}$ and $r_{2}$ are random numbers uniformly distributed in the range $[0,1], w_{\min }$ is $0.4, w_{\max }$ is 0.9 , and $k_{\max }$ is 1,000 , i.e., maximum iteration set as the termination criteria for each trial.

Based on comparing GA and TS, the design was done using a PI controller for the four-phase interleaved boost converter circuit. GA and TS parameter search is designed as original. Both GA and TS will be canceled when processing the construction or making a repletion of up to 1,000 times. GA and TS will not be discussed. But they show more details of GA in [27, 28] and TS in [29-31] accordingly. The algorithm of the two searches mentioned works by using MATLAB.

For designing the PI controller, its parameter PI is set for searching the following spaces: $K_{p}$ ranges $[0,10]$ and $K_{i}$ ranges $[50,100]$. The processing designed for 50 experiment 


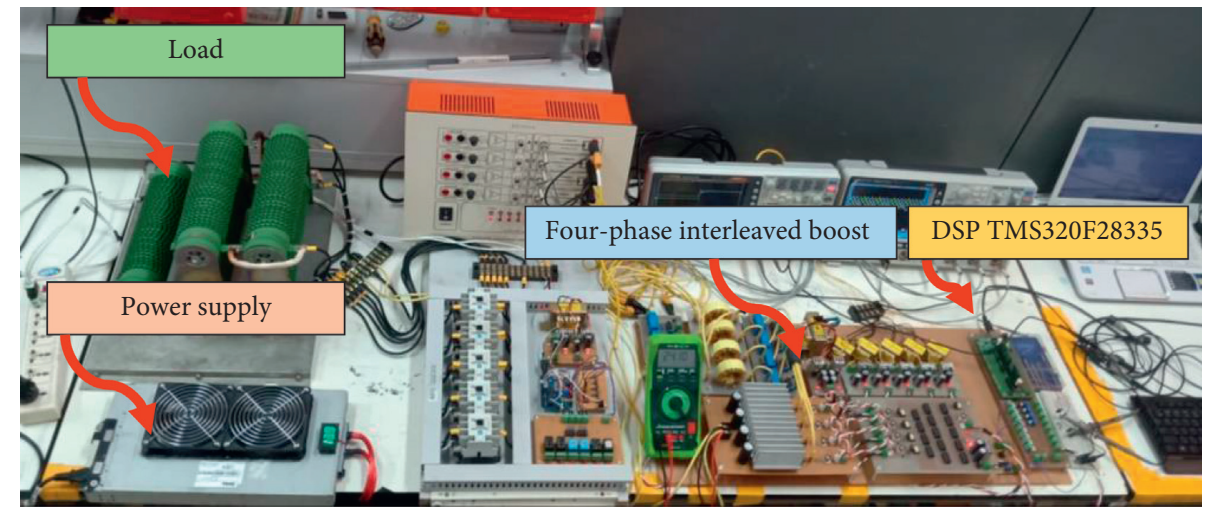

FIGURE 11: Shows the design of the PI controller using PSO for controlling Four-phase interleaved boost converter circuit voltage for the experiment.

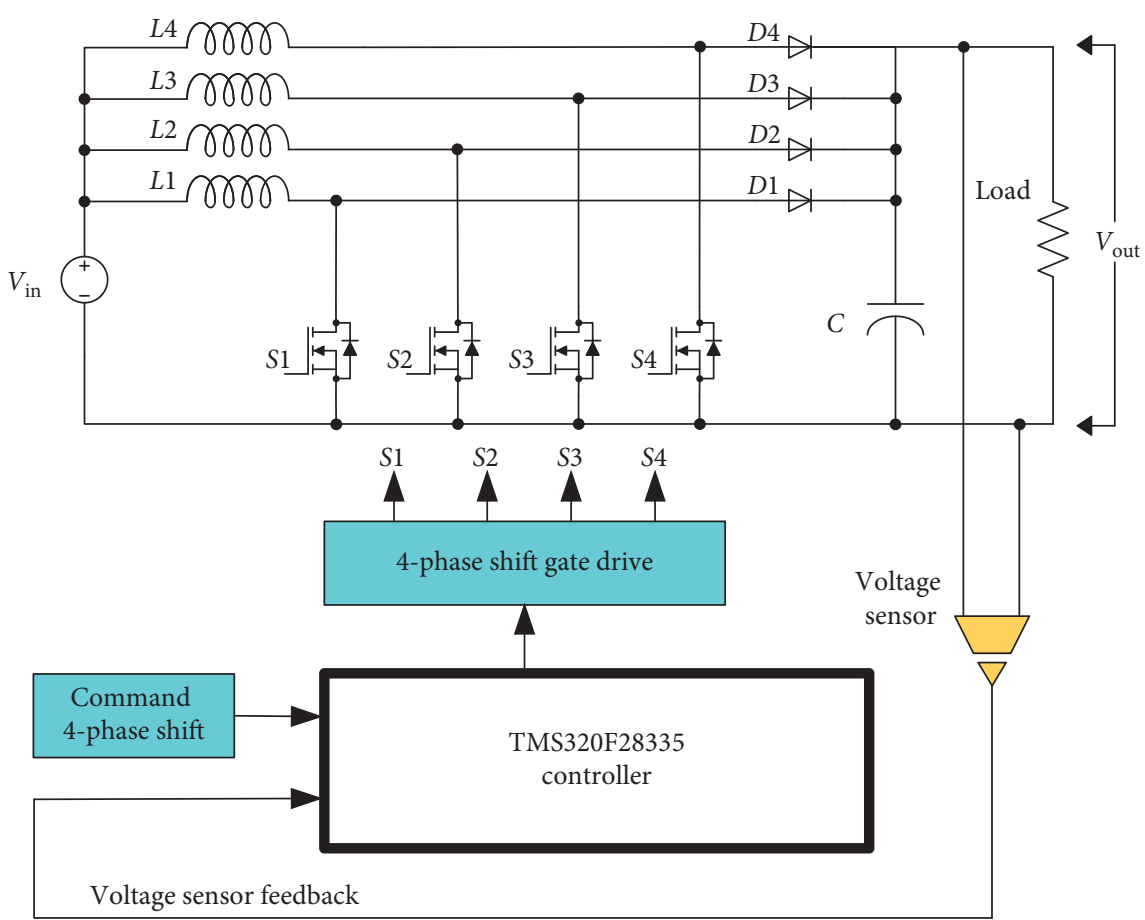

FIGURE 12: Diagram of designing a PI controller using PSO for controlling four-phase interleaved boost converter circuit voltage.

TABLE 1: Summary table of the parameter value of the four-phase interleaved boost converter circuit.

\begin{tabular}{lc}
\hline Parameter & Parameter value \\
\hline Input voltage & $13.8 \mathrm{~V}$ \\
Inductor & $586.5 \mu \mathrm{H}$ \\
Capacitor & $100 \mu \mathrm{F}$ \\
Angle of switching & $90^{\circ}$ \\
Frequency of switching & $25 \mathrm{kHz}$ \\
\hline
\end{tabular}

searches starts with different search points to find the best value. After the search processing stops, the parameter value of the PI controller is obtained using GA, TS, and PSO methods as shown in equations (15)-(17) accordingly. The result of the simulation of the controller system is shown in Figure 13.

$$
\begin{aligned}
\left.G_{c}(s)\right|_{\text {PI_GA }} & =0.435+\frac{1286}{s}, \\
\left.G_{c}(s)\right|_{\text {PI_TS }} & =0.325+\frac{1256}{s}, \\
\left.G_{c}(s)\right|_{\text {PI_PSO }} & =0.413+\frac{1413}{s} .
\end{aligned}
$$

Based on Figure 11, the response of four-phase interleaved boost converter circuit simulation and time for searching can be seen in Table 2 where $T_{\mathrm{r}}$ is the rise time, $M_{\mathrm{p}}$ is the maximum percent overshoot, $T_{\mathrm{s}}$ is the settling time, and $e_{\mathrm{ss}}$ is the steady state error. Based on Table 2, PSO is able to search the PI parameter value for the four-phase interleaved boost converter with minimum time. Moreover, the 


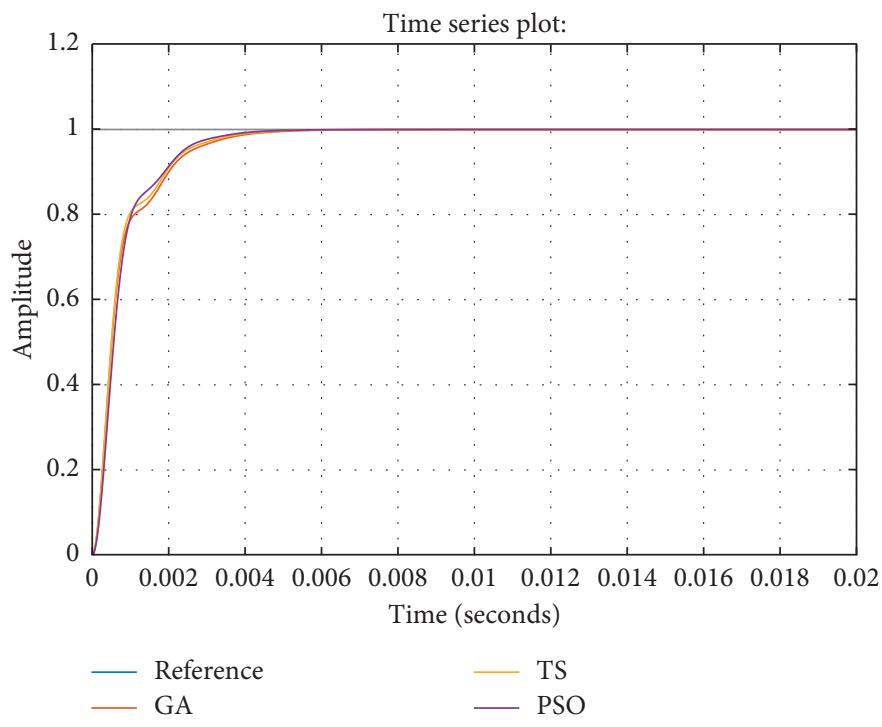

FIGURE 13: Result of response simulation of PI controller voltage with GA, TS, and PSO.

TABle 2: System responses by the PI controller.

\begin{tabular}{|c|c|c|c|c|c|}
\hline \multirow{2}{*}{ Entry } & \multicolumn{4}{|c|}{ System responses by PI } & \multirow{2}{*}{ Search time (sec.) } \\
\hline & $T_{\mathrm{r}}(\mathrm{sec})$. & $M_{\mathrm{p}}(\%)$ & $T_{\mathrm{s}}(\mathrm{sec})$. & $e_{\mathrm{ss}}(\%)$ & \\
\hline GA & 0.0022 & 0.00 & 0.0095 & 0.00 & 176.14 \\
\hline TS & 0.002 & 0.00 & 0.0085 & 0.00 & 104.35 \\
\hline PSO & 0.00185 & 0.00 & 0.0075 & 0.00 & 44.83 \\
\hline
\end{tabular}

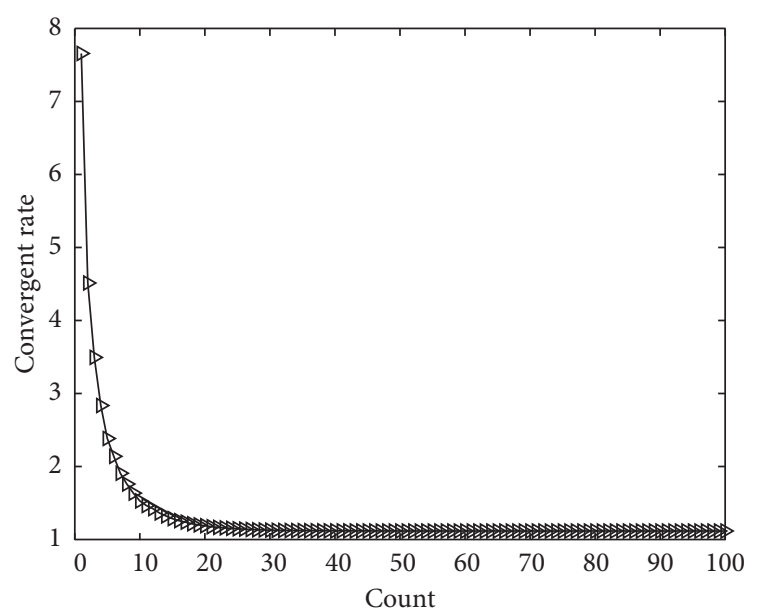

FIGURE 14: Shows the result of convergence towards the answer while searching the PI value using PSO search.

control system of the four-phase interleaved boost converter also gives a quick response when rise time and settling time have the best value and show the result of convergence to the answer of PI search value using PSO as shown in Figure 14.

\section{Experiment Result}

The test on the PI controller with the PSO search for controlling voltage of the four-phase interleaved boost converter uses 4 sets of original boost converter circuit working in parallel. The operation is done with 90-degree interface and has a voltage sensor sending electrical signals to the DSP board TMS320F28335 working with MATLAB/ Simulink of sampling time at 0.0001 second.

In this research, the voltage level was kept at 2 levels, i.e., $20 \mathrm{~V}$ and $24 \mathrm{~V}$. The result of the experiment shows the stability condition treatment of circuit voltage while changing load without the control system and voltage control of $20 \mathrm{~V}$ and $24 \mathrm{~V}$ while changing load accordingly. The data collection was done using digital storage scope GW Instek GDS-3000 Series $150 \mathrm{MHz} 4$ input channels.

Based on the experimental results of circuit voltage treatment while changing load without a control system with voltage control of $20 \mathrm{~V}$ and $24 \mathrm{~V}$ as shown in Figures 15 and 16 , it was found that the output voltage of the circuit dropped significantly when the load was increased. The figure shows that the system was unstable to maintain the output voltage level to be constant.

From Figure 17, the inductor current phases 1 and 2 are indicated with switch signals $S 1$ and $S 2$, respectively. The signals $S 1$ and $S 2$ are determined to operate the inductor current in 90 degree of differentiation. It can be seen that when both switches are on, there will be increase in current in the load. On the other hand, when both switches are off, current will decrease. Therefore, experiment results confirm the theoretical analysis. From Figure 18, the current of the four-phase interleaved boost converter is investigated for every 90-degree switch signal overlapping. It can be seen that all inductor currents still appear according to the switch signals $S 1$ and $S 2$, respectively.

For controlling PI controller voltage at $20 \mathrm{~V}$, the gained values of the PI controller using three optimization algorithms of GA, TS, and PSO are applied to examine the response and the stability of the circuit voltage. The results are shown in Figures 19-24.

Figures 19, 21, and 23 show the result of voltage response and current when the gained values of the PI controller are applied in GA, TS, and PSO, respectively. The initial voltage input is set at $13.8 \mathrm{~V}$, and this study focused on the voltage 


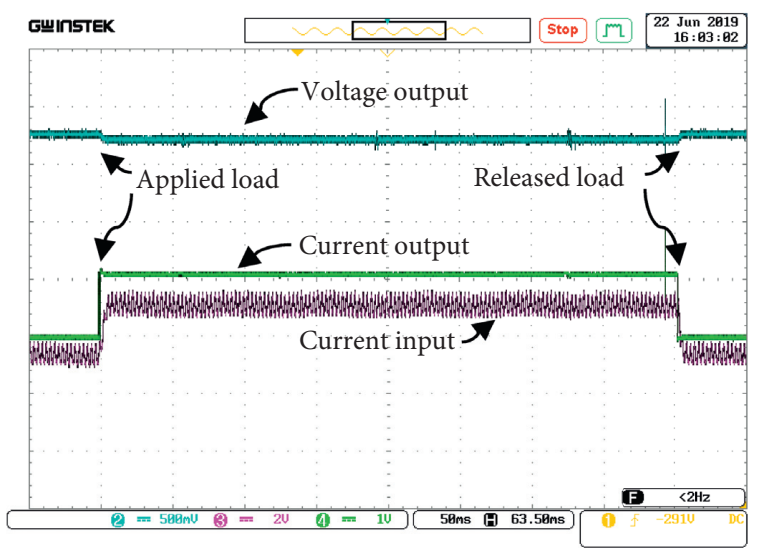

FIGURE 15: Result of the four-phase interleaved boost converter circuit at voltage of $20 \mathrm{~V}$ without the controller.

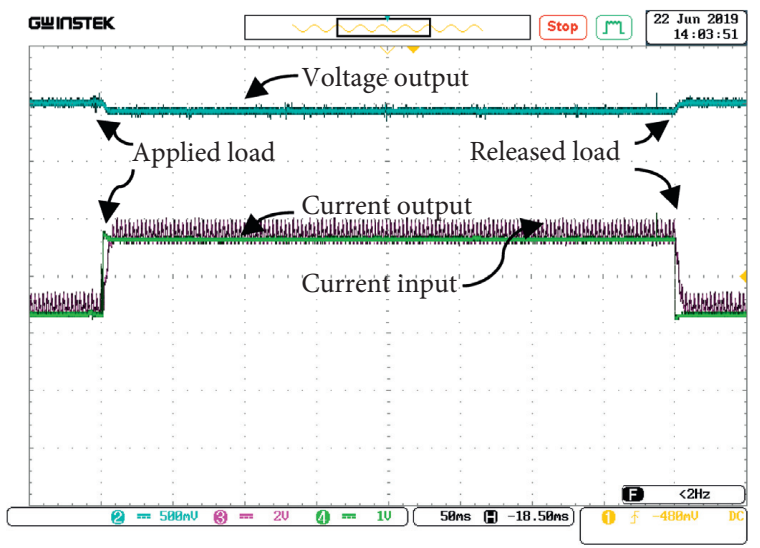

FIGURE 16: Result of the four-phase interleaved boost converter circuit at voltage of $24 \mathrm{~V}$ without the controller.

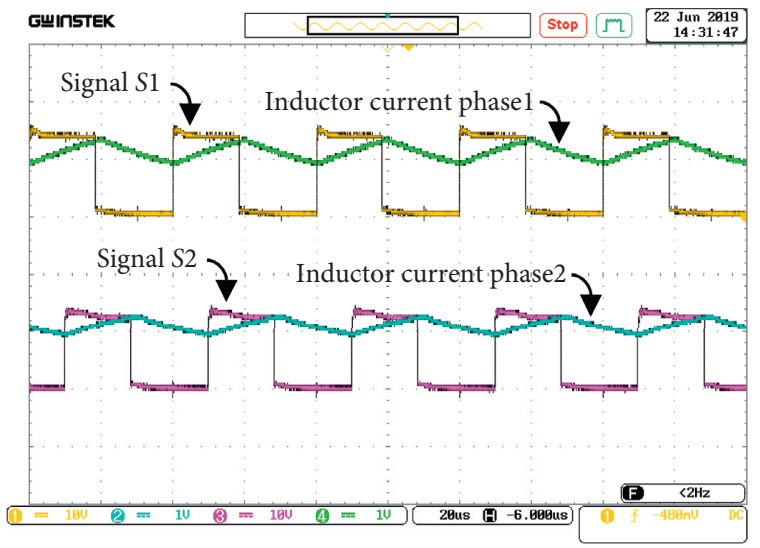

FIGURE 17: Result of inductor current when compared to switch operation of the four-phase interleaved boost converter circuit.

output controlling at $20 \mathrm{~V}$. Three algorithms can provide good response results and also can remain the steady state of voltage output instantaneously. It could enter the condition within less than 20 milliseconds (ms) and could maintain the

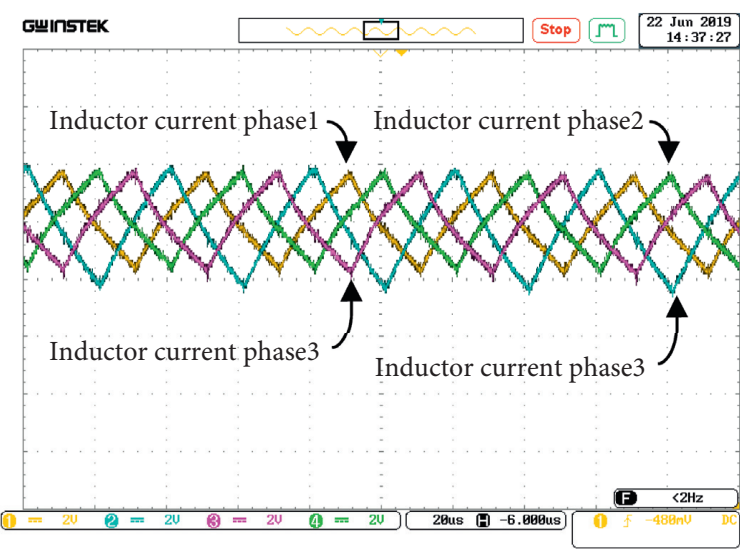

FIgURE 18: Result of inductor current of the 4 phases of the fourphase interleaved boost converter circuit.

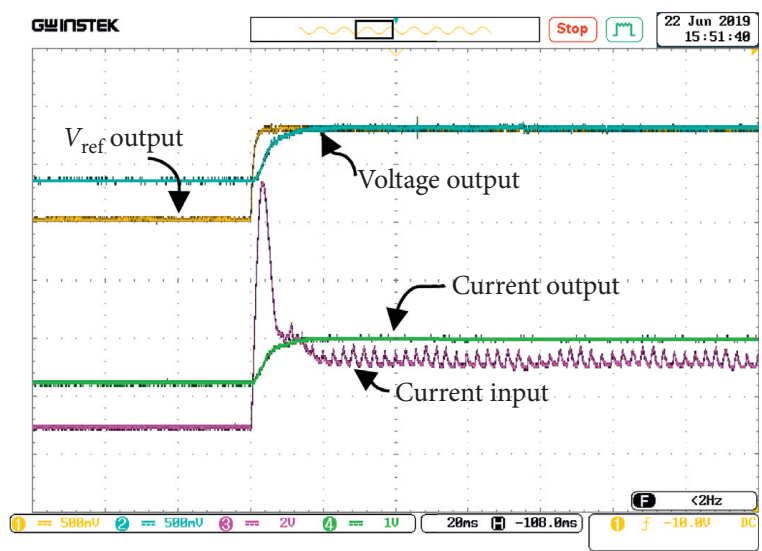

FIgURE 19: Result of voltage response and current using a PI controller with GA search.

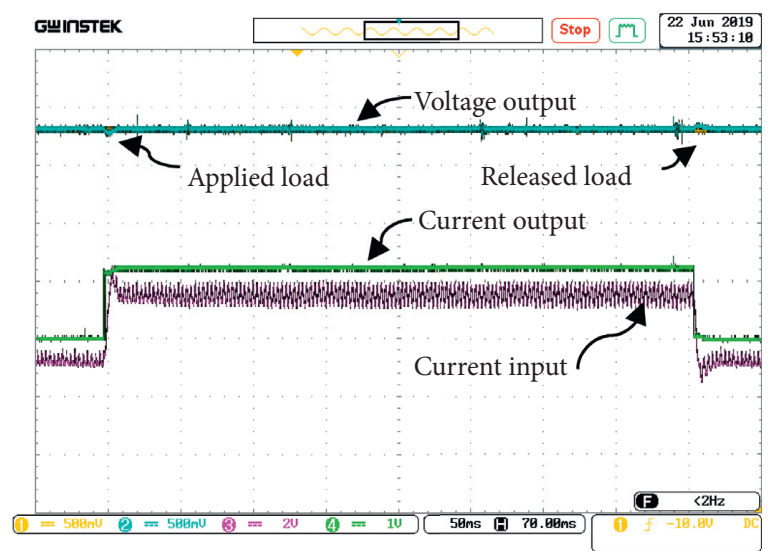

FIgURE 20: Result of maintaining voltage stability and current while changing load using a PI controller with GA search.

output voltage both when in stable load condition and while changing load. The system could enter the stable condition quickly while having a very satisfactory less changing of voltage. Figures 20, 22, and 24 illustrate the results when 


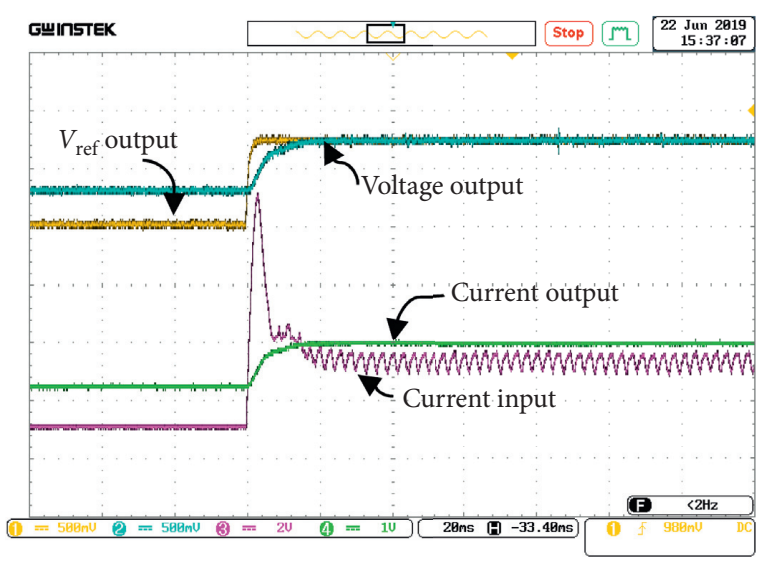

FIgURE 21: Result of voltage response and current using a PI controller with TS search.

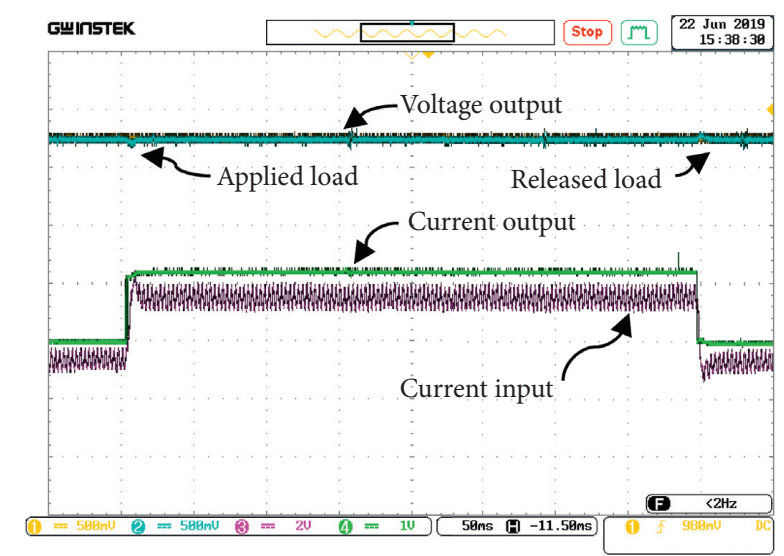

FIGURE 22: Result of maintaining voltage stability and current while changing load using a PI controller with TS search.

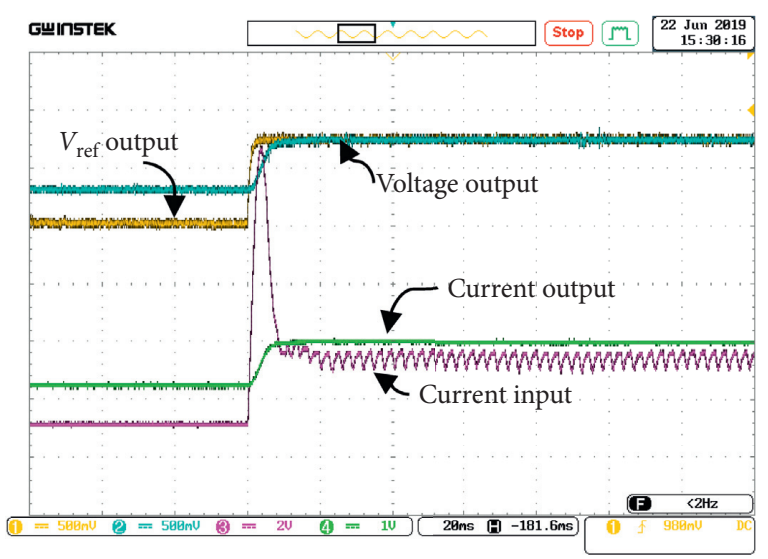

FIGURE 23: Result of voltage response and current using a PI controller with PSO search.

changing the load. It can be seen that the stability of voltage output from three algorithms still remains unchanged although load has changed. Table 3 shows the system response by the PI controller at $20 \mathrm{~V}$.

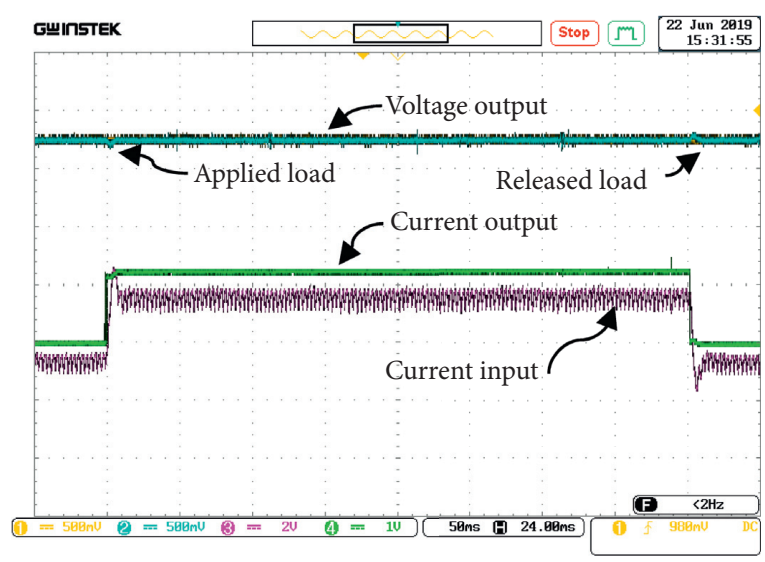

FIGURE 24: Result of maintaining voltage stability and current while changing load using a PI controller with PSO search.

TAble 3: System response by the PI controller at $20 \mathrm{~V}$.

\begin{tabular}{lcccc}
\hline \multirow{2}{*}{ Entry } & \multicolumn{5}{c}{ System responses by PI } \\
& $T_{\mathrm{r}}(\mathrm{ms})$ & $M_{\mathrm{p}}(\%)$ & $T_{\mathrm{s}}(\mathrm{ms})$ & $e_{\mathrm{ss}}(\%)$ \\
\hline GA & 12 & 0.00 & 16 & 0.00 \\
TS & 14 & 0.00 & 17 & 0.00 \\
PSO & 6 & 0.00 & 8 & 0.00 \\
\hline
\end{tabular}

In summary, the system response of voltage output from the PI controller at $20 \mathrm{~V}$ using GA, TS, and PSO can be concluded as in Table 3. Also, the PI control with PSO search had the quickest response to reference signal when compared to GA and TS. The PSO establishes the lowest rise time at $6 \mathrm{~ms}$ and the lowest time to steady state at $8 \mathrm{~ms}$. Therefore, the PSO is the best algorithm in controlling the voltage output at $20 \mathrm{~V}$.

In order to control voltage output at $24 \mathrm{~V}$, the same PI controller gained values as one for $20 \mathrm{~V}$ are applied in GA, TS, and PSO, respectively. It was found that GA, TS, and PSO had a quick response to reference signal and could enter the condition in less than $20 \mathrm{~ms}$. Figures 25-27 show the result of voltage response and current when the gained values of the PI controller are applied in GA, TS, and PSO, respectively. The initial voltage input is set at $13.8 \mathrm{~V}$. In the experiment case, the voltage output is controlled at $24 \mathrm{~V}$.

Three optimization algorithms can provide good response results and also can remain the steady state of voltage output similar to the case of $20 \mathrm{~V}$ controlling. Figures 28-30 show the results, when changing the load. It can be seen that the stability of voltage output from three algorithms still remains unchanged although load has changed. Table 4 shows the system response by the PI controller at $24 \mathrm{~V}$.

As in Table 4, the system response of voltage output by the PI controller at $24 \mathrm{~V}$ using GA, TS, and PSO can be concluded. The GA performs at the lowest rise time of $7 \mathrm{~ms}$, whereas GA needs $16 \mathrm{~ms}$ in converging to steady state. However, for PSO algorithm, rise time is $7.2 \mathrm{~ms}$ which is close to the GA algorithm while the time to go to the steady state is about $10 \mathrm{~ms}$ which is less than GA. The PSO, therefore, provides most suitable algorithm in controlling 


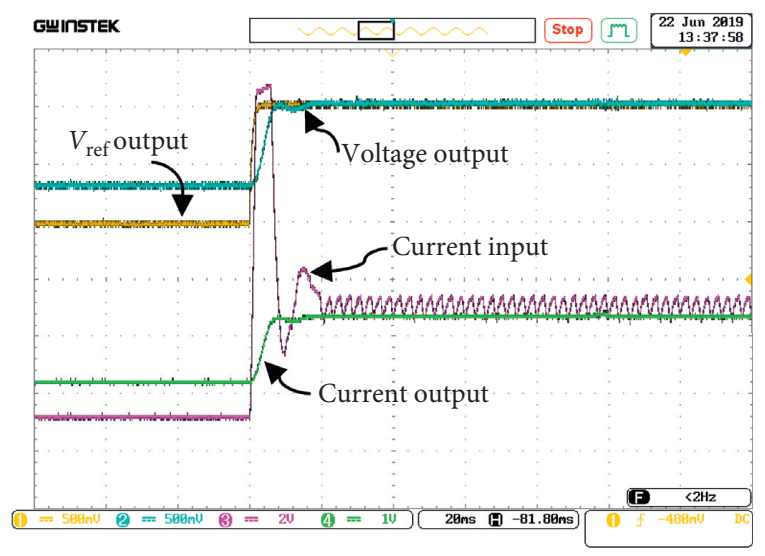

Figure 25: Result of voltage response and current using a PI controller with GA search.

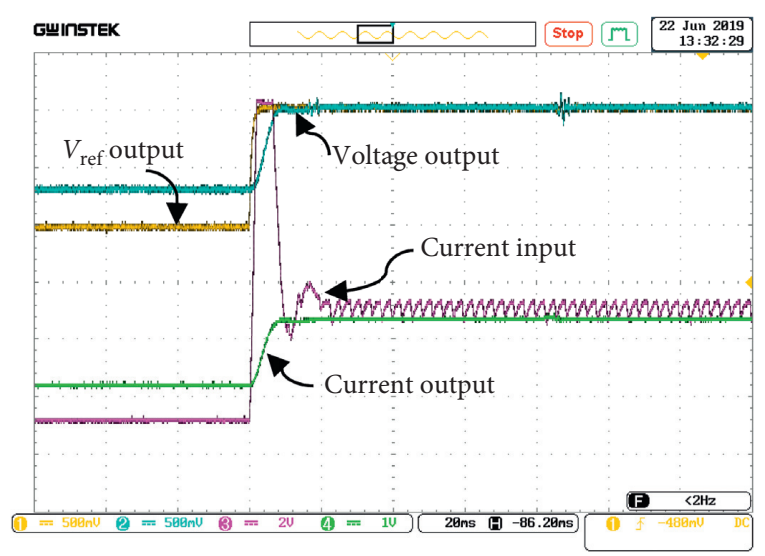

FIGURE 26: Response of voltage and current using a PI controller with TS search.

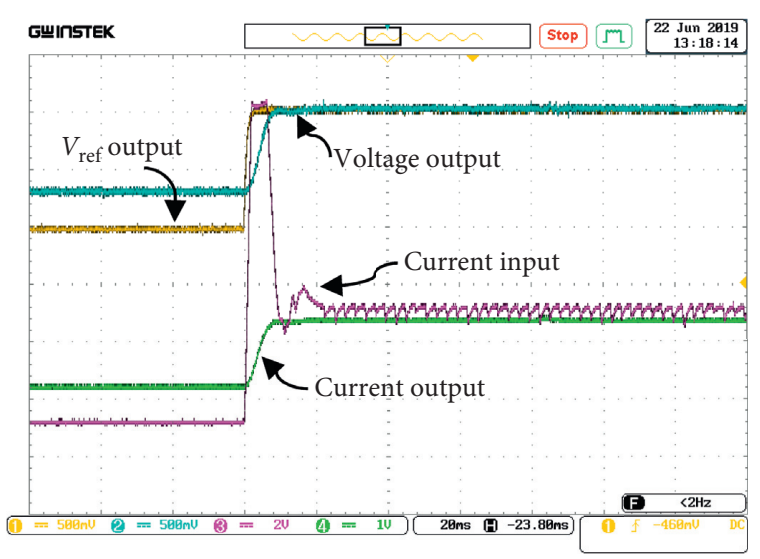

FIgURE 27: Result of voltage response and current using a PI controller with PSO search.

the voltage output at $24 \mathrm{~V}$ compared to GA and TS as well as controlling voltage at $20 \mathrm{~V}$.

The proposed control algorithm though applied for the boost converter of $20 \mathrm{~V}$ and $24 \mathrm{~V}$ using PSO exhibits the best performance in the aspect of system response and stability. The experimental results agree with $[32,33]$ although

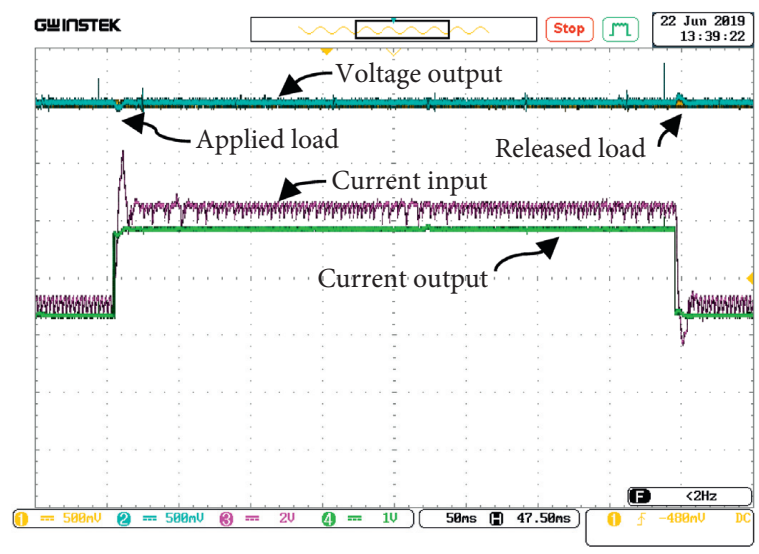

FIGURE 28: Result of maintaining voltage stability and current while changing load using a PI controller with TS search.

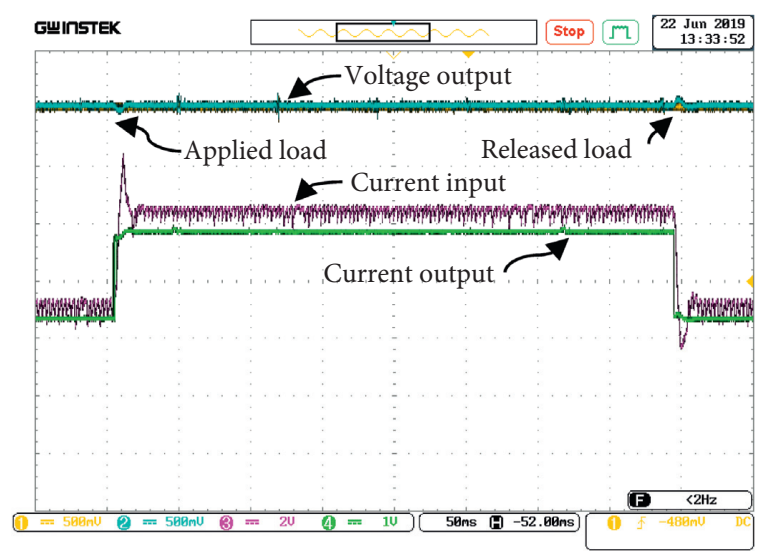

FIGURE 29: Result of maintaining voltage stability and current while changing load using a PI controller with TS search.

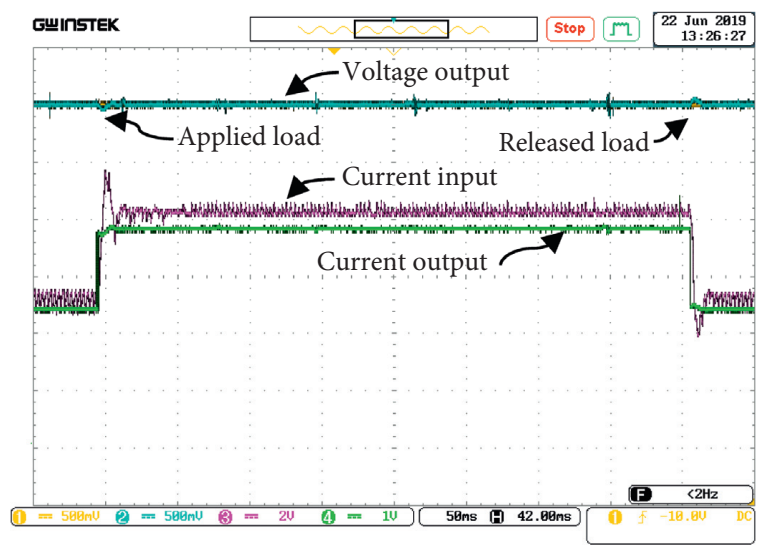

FIGURE 30: Result of maintaining voltage stability and current while changing load using a PI controller with PSO search.

TABle 4: System response by the PI controller at $24 \mathrm{~V}$.

\begin{tabular}{lcccc}
\hline \multirow{2}{*}{ Entry } & \multicolumn{4}{c}{ System responses by PI } \\
& $T_{\mathrm{r}}(\mathrm{ms})$ & $M_{\mathrm{p}}(\%)$ & $T_{\mathrm{s}}(\mathrm{ms})$ & $e_{\mathrm{ss}}(\%)$ \\
\hline GA & 7 & 0.00 & 16 & 0.00 \\
TS & 7.2 & 0.00 & 15 & 0.00 \\
PSO & 7.2 & 0.00 & 10 & 0.00 \\
\hline
\end{tabular}


applied for the four-phase interleaved boost converter. However, there are no overshoot and time to steady state reaches faster than their study.

\section{Conclusion}

In this paper, the four-phase interleaved boost converter circuit is controlled by the PI controller. In order to tune the gains of the PI controller, the PSO, GA, and TS and metaheuristic optimizations, are applied. In testing the control system, the response of the four-phase interleaved boost converter obtained by PSO has the rise time and setting time faster than the GA and TS methods. Additionally, it is found that the tracing and controlling response result of output voltage is extremely satisfactory when load condition is constant and while changing the load. It can be concluded that the four-phase interleaved boost converter circuit using the PI controller tuned gains by PSO is greatly effective for regulating the voltage in a real system.

\section{Data Availability}

No data were used to support this study.

\section{Conflicts of Interest}

The authors declare that they have no conflicts of interest.

\section{Acknowledgments}

The authors would like to acknowledge Department of Electrical Engineering and Faculty of Engineering, Pathumwan Institute of Technology, for the financial support and facilities. They would also like to show their gratitude to Assoc. Prof. Dr. Decha Pungdaorueng and Asst. Prof. Dr. Wachirapond Permpoonsinsup who gave very useful advices and suggestions for completing this research.

\section{References}

[1] C. Jain and B. Singh, "An adjustable DC link voltage-based control of multifunctional grid interfaced solar PV system," IEEE Journal of Emerging and Selected Topics in Power Electronics, vol. 5, no. 2, pp. 651-660, 2017.

[2] Y. A. Zuniga-Ventura, D. Langarica-Cordoba, J. LeyvaRamos, L. H. Diaz-Saldierna, and V. M. Ramirez-Rivera, "Adaptive backstepping control for a fuel cell/boost converter system," IEEE Journal of Emerging and Selected Topics in Power Electronics, vol. 6, no. 2, pp. 686-695, 2018.

[3] P. Mungporn, P. Thounthong, S. Sikkabut et al., "Differential flatness-based control of current/voltage stabilization for a single-phase PFC with multiphase interleaved boost converter," in Proceedings of the European Conference on Electrical Engineering and Computer Science, pp. 124-130, Athens, Greece, November 2017.

[4] A. Marcos-Pastor, E. Vidal-Idiarte, A. Cid-Pastor, and L. Martinez-Salamero, "Interleaved digital power factor correction based on the sliding-mode approach," IEEE Transactions on Power Electronics, vol. 31, no. 6, pp. 46414653, 2016.
[5] D. Apablaza and J. Munoz, "Laboratory implementation of a boost interleaved converter for PV applications," IEEE Latin America Transactions, vol. 14, no. 6, pp. 2738-2743, 2016.

[6] F. H. Aghdam and M. Abapour, "Reliability and cost analysis of multistage boost converters connected to PV panels," IEEE Journal of Photovoltaics, vol. 6, no. 4, pp. 981-989, 2016.

[7] R. Seyezhai and B. L. Mathur, "A comparison of three-phase uncoupled and directly coupled interleaved boost converter for fuel cell applications," International Journal on Electrical Engineering and Informatics, vol. 3, no. 3, pp. 394-407, 2011.

[8] S. Banerjee, A. Ghosh, and N. Rana, "Design and fabrication of closed loop two-phase interleaved boost converter with type-III controller," in Proceedings of the IECON 2016-42nd Annual Conference of the IEEE Industrial Electronics Society, pp. 3331-3336, Florence, Italy, October 2016.

[9] C. Kiree, D. Kumpanya, S. Tunyasrirut, and D. Puangdownreong, "PSO-based optimal PI(D) controller design for brushless DC motor speed control with back EMF detection," Journal of Electrical Engineering and Technology, vol. 11, no. 3, pp. 715-723, 2016.

[10] S. Banerjee, A. Ghosh, and N. Rana, "An improved interleaved boost converter with PSO-based optimal type-III[ controller," IEEE Journal of Emerging and Selected Topics in Power Electronics, vol. 5, no. 1, pp. 323-337, 2017.

[11] M. Calvini, M. Carpita, A. Formentini, and M. Marchesoni, "PSO-based self-commissioning of electrical motor drives," IEEE Transactions on Industrial Electronics, vol. 62, no. 2, pp. 768-776, 2015.

[12] S. W. Shneen, A. Z. Salman, Q. A. Jawad, and H. Shareef, "Advanced optimal by PSO-PI for DC motor," Indonesian Journal of Electrical Engineering and Computer Science, vol. 16, no. 1, pp. 165-175, 2019.

[13] M. Rasheed, R. Omar, M. Sulaiman, and W. Abd Halim, "A modified cascaded h-bridge multilevel inverter based on particle swarm optimisation (PSO) technique," Indonesian Journal of Electrical Engineering and Computer Science, vol. 16, no. 1, pp. 41-45, October 2019.

[14] M. Rasheed, R. Omar, M. Sulaiman, and W. A. Halim, "Particle swarm optimisation (PSO) algorithm with reduced numberof switches in multilevel inverter (MLI)," Indonesian Journal of Electrical Engineering and Computer Science, vol. 14, no. 3, pp. 1114-1124, 2019.

[15] M. Arun Devi, K. Valarmathi, and R. Mahendran, "Ripple current reduction in interleaved boost converter by using advanced PWM techniques," in Proceedings of the IEEE International Conference on Advanced Communication Control and Computing Technologies (lCACCCT), pp. 115-119, Ramanathapuram, India, May 2014.

[16] S. Kaščák, M. Praženica, M. Jarabicová, and R. Koňarik, "Analysis of four-phase interleaved boost converter," Transactions on Electrical Engineering, vol. 6, no. 4, pp. 110-113, 2017.

[17] S. Kascak, M. Prazenica, M. Jarabicova, and R. Konarik, "Four-phase interleaved boost converter: theory and applications," WSEAS Transactions on Power Systems, vol. 13, pp. $272-282,2018$.

[18] S. Kascak, M. Jarabicova, and R. Konarik, "Four phase interleaved boost converter-analysis and verification," Acta Electrotechnica et Informatica, vol. 18, no. 1, pp. 35-40, 2018.

[19] C. W. Reynolds, "Flocks, herds and schools: a distributed behavioral model," ACM SIGGRAPH Computer Graphics, vol. 21, no. 4, pp. 25-34, 1987.

[20] J. Kennedy and R. Eberhart, Swarm Intelligence, Morgan Kaufman, Burlington, MA, USA, 2001. 
[21] J. Kennedy and R. Eberhart, "Particle swarm optimization," in Proceeding of IEEE International Conference Neural Networks, vol. IV, pp. 1942-1948, Perth, Australia, 1995.

[22] K. S. Kumar, K. K Aggarwal, and J. Singh, "Design of fuzzy models through partical swarm optimization," in Integrated Intelligent Systems for Engineering Design, pp. 43-62, IOS press, Amsterdam, Netherlands, 2006.

[23] R. Eberhart and Y. Shi, "Comparing inertial weights and constriction factor in particle swarm optimization," in Proceeding of Internationnal Congress on Evolutioning Computation, pp. 84-88, La Jolla, CA, USA, 2000.

[24] Texas Instruments, TMS320F28335, Digital Signal Controller, Texas Instruments, Dallas, TX, USA, 2007.

[25] The Math Works Inc., MATLAB/Simulink User's Guide, The Math Works Inc., Natick, MA, USA, 1998.

[26] V. Viswanatha, "A complete mathematical modeling, simulation and computational implementation of boost converter via MATLAB/Simulink," International Journal of Pure and Applied Mathematics, vol. 114, no. 10, pp. 407-419, 2017.

[27] D. E. Goldberg, Genetic Algorithm in Search, Optimization, and Machine Learning, Addison-Wesley Publishing, Boston, MA, USA, 1989.

[28] D. E. Goldberg, "Genetic and evolutionary algorithms come of age," Communications of the ACM, vol. 37, no. 3, pp. 113-119, 1994.

[29] F. Glover, "Tabu search-Part I," ORSA Journal on Computing, vol. 1, no. 3, pp. 190-206, 1989.

[30] F. Glover, "Tabu search-Part II," ORSA Journal on Computing, vol. 2, no. 1, pp. 4-32, 1990.

[31] F. Glover, "Parametric tabu-search for mixed integer programs," Computers \& Operations Research, vol. 33, no. 9, pp. 2449-2494, 2006.

[32] A. Ghosh and S. Banerjee, "Control of switched-mode boost converter by using classical and optimized type controllers," CEAI, vol. 17, no. 4, pp. 114-125, 2015.

[33] A. Ghosh, S. Banerjee, M. K. Sarkar, and P. Dutta, "Design and implementation of type-II and type-III controller for DC-DC switched-mode boost converter by using K-factor approach and optimisation techniques," IET Power Electronics, vol. 9, no. 5, pp. 938-950, 2016. 